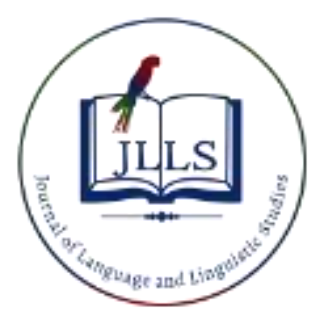

Available online at www.jlls.org

JOURNAL OF LANGUAGE AND LINGUISTIC STUDIES

ISSN: $1305-578 \mathrm{X}$

Journal of Language and Linguistic Studies, 16(2), 849-863; 2020

\title{
Family reminiscence scale: A measure of early communicative context
}

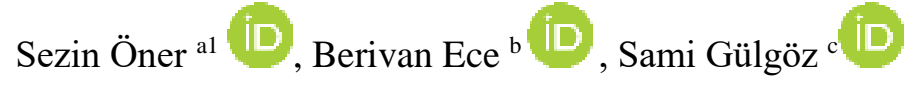 \\ ${ }^{a}$ Kadir HasUniversity, İstanbul, Turkey \\ ${ }^{b, c}$ Koc University, İstanbul, Turkey
}

\author{
APA Citation: \\ Öner, S., Ece, B., \& Gülgöz, S. (2020). Family reminiscence scale: A measure of early communicative context. Journal of Language and \\ Linguistic Studies, 16(2), 849-863. \\ Submission Date:27/01/2020 \\ Acceptance Date:07/03/2020
}

\begin{abstract}
We developed and validated the Family Reminiscence Scale (FARS) in which adults rate their frequency of reminiscing with their parents about childhood experiences. In three studies, we characterized how FARS was related to adults' recollections of their earliest memories in different cultural contexts. First, we examined the factorial structure of FARS and obtained two factors of reminiscing: first-time events and general-recurrent events. In the second study, confirmatory factor analyses were conducted, in which we established measurement invariance across gender and age groups. In Study 3, we tested the factorial structure of FARS in an American sample to ensure cross-cultural invariance. We also showed that the two factors were differentially related to the phenomenology of earliest memories in samples from Turkey and United States (Study 2 \& Study 3). Overall, FARS was found to be reliable and valid to measure for adult samples to assess the quality of the linguistic input during childhood. Predictive value of FARS has been shown across different gender, age, and culture groups, underlining the organizational role of the early communicative context in the phenomenology and linguistic style of adults' early memories.
\end{abstract}

(C) 2020 JLLS and the Authors - Published by JLLS.

Keywords: Earliest memories; childhood amnesia; parental reminiscing; linguistic analyses; confirmatory factor analysis

\section{Introduction}

When adults are asked about their childhood experiences, they hardly remember instances from the period of infancy and early childhood. This phenomenon, childhood amnesia, has been consistently documented across cultures despite variations in the age of the earliest memory Siegel, \& Brown, 1993. Theoretical accounts include cognitive, social, cultural, and linguistic mechanisms to explain childhood amnesia. Substantial evidence emphasized the role of early reminiscing environment on the emergence and quality of autobiographical remembering (Fivush, Haden, Reese, 2006). This is not surprising, as parent-child interaction forms the context in which early memories are formed (Nelson \& Fivush, 2004).

\footnotetext{
1 Corresponding author. Tel.: +90 (212) 5336532

E-mail address: sezin.oner@khas.edu.tr
} 
Communication with parents on past events constitutes a form of rehearsal for the child, but more importantly, serves as a guide for remembering.

Research with children provided evidence supporting the social-interactionist perspective (Nelson \& Fivush, 2004) where conversational interactions with parents enhance rehearsal and accessibility (Fivush, 2011) and guide the organization of experiences. Children of elaborative parents reported earlier, more detailed early memories (Fivush et al., 2006). Not only children, but adolescents (Jack, MacDonald, Reese \& Hayne, 2009) and adults (Wang, 2006) who experienced more elaborative reminiscing in their childhood also reported earlier childhood memories.

Results of studies with adults also found supporting evidence by examining factors like gender and culture. For example, women report earlier, longer, more detailed memories than men, which is attributed to the parental tendency to engage in more frequent and elaborative memory talk with female children (Kingo, Berntsen, \& Krøjgaard, 2013; Howes, Siegel \& Brown, 1993; Mullen, 1994). With respect to culture, compared to Western cultures, in Eastern cultures, earliest memories are reported from a later age (Wang, 2006) and such findings are explained with the tendency of the Eastern parents to emphasize the communal aspects of self rather than the individual (e.g., child), leading to a later organization of personal memories (Fivush, 2011).

One approach to investigating this issue is to examine individuals' current views of their early conversations with their parents and their earliest memories. Several studies demonstrated that parental involvement and warm interactions were associated with more narrative exchanges, which were associated with earlier and denser reports of earliest memories (Artioli, Cicogna, Occhionero \& Reese, 2012; Peterson, Smorti, \& Tani, 2008). Although such findings are consistent with the socialinteractionist explanation, they are not conclusive because they emphasized the affective aspects of the parent-child relationship, and neglected the nature of early parental memory-talk.

The parent's ability to reflect significant instances for the child may reveal how attuned the parent is and about the quality of the interaction. In cases where parents favor reminiscing what they find important without focusing on what is significant for child, it becomes more difficult for the child to organize a coherent memory for own experiences (Oppenheim \& Koren-Karie, 2014). Similarly, parental communication on shared events, rather than the child's unique experiences, would influence not only the age of the earliest memories, but also, the self-relevance and specificity of childhood memories. Therefore, the age and the phenomenology of earliest memories may be affected by the content and amount of parental reminiscing devoted to child's own experiences.

In studies with children, the amount of parental reminiscing has been assessed through narratives (Fivush, Bohanek, \& Duke, 2008) and observations (Kuebli, Butler \& Fivush, 2008) of parent-child communication. In addition, Do You Know? scale by Duke and colleagues (Duke, Fivush, Lazarus, \& Bohanek, 2003) assessed the amount of information that children acquired through family conversations, writings. Although this measure may provide insight about the amount of parent-child communication, it is a measure of children's knowledge of family knowledge, not specifically focused on the dyadic conversation. On the other hand, studies with adult samples have not targeted the early verbal interactions. The effect of communication was inferred from either the cultural-linguistic templates (Wang, 2006) or the affective quality of the parent-child relationship (Peterson et al., 2008). Addressing this gap, we developed a measure for adults to characterize early family reminiscing from the perspective of the adult rememberer and to assess the amount parental reminiscing on childhood experiences. We find these important considering significant implications associated with early communicative context. First, the child learns event components necessary to encode for future recollection enhancing the development of encoding skills (Hedrick, Haden \& Ornstein, 2009). Second, frequent reminiscing functions as scaffolding for the child's production of memory narratives (Artioli 
et al., 2012). The child learns narrative schemas which should lead to earlier development of memory and narrative skills. Finally, reminiscing of childhood events functions as a rehearsal, enhancing their subsequent recollection (Fivush et al., 2006). By the same token, parental reminiscing should lead to a higher number of events that adults report remembering, although they are actually reconstructed on the basis of family reminiscing. Considering these effects of parent-child reminiscing on autobiographical remembering, we believe that the Family Reminiscence Scale presents a valuable and useful tool for autobiographical memory research in general, and for earliest memory research in particular.

\subsection{Family Reminiscence Scale}

We developed the Family Reminiscence Scale (FARS) and tested its psychometric properties. In FARS, we focused on the retrospective assessment of the frequency of parent-child reminiscing. In the item-generation phase, we selected common themes of early childhood, particularly the preschool years. We created items about typical events expected to occur in any child's life. We included unique events (e.g., starting to talk) and events that children routinely encounter (e.g., playing with toys), which differ in specificity and distinctiveness. We considered both negative and positive events, as valence may influence the amount and content of parent-child communication (Laible, 2011; Sales, Fivush, \& Peterson, 2003) and consequently its function (Alea \& Bluck, 2003). Parental separation and conflict were found as frequent topics in negative conversations (Sales, et al., 2003), however, although these events may be shared with children, they are essentially autobiographical memories of the parents. Therefore, we focused on more common experiences like injuries. For positive events, we selected leisure activities (Sales et al., 2003). It is quite likely that event type may be unrelated to differences in parent-child communication however, our goal was to capture various forms of events to assure adequate representation of various contexts of parent-child communication and to minimize any bias different events may introduce.

Items were generated through discussions among lab members and the final items were selected with three concerns in mind: a) to include specific and recurring events, b) to include negative and positive events, and c) to keep the measure brief.

\subsection{Current Research}

The goal of the current research was to propose a reliable and practical tool to assess the frequency of parent-child communication about the child's early experiences. In the first study, we examined the factorial structure of the FARS in a Turkish sample. In the second study, we conducted a confirmatory factor analysis using a different sample from Turkey to validate the factorial structure. FARS factors were also examined in relation to the phenomenological features of earliest memories, which served as one line of validity check. Finally, in the third study, we tested FARS with a sample from the United States to ensure cross-cultural stability.

\section{Study 1}

\subsection{Method}

\subsubsection{Participants.}

Participants were 494 adults from Turkey with an age range of 18 to $60(M=34.48 ; S D=10.87$; $76.4 \%$ female). Participants were volunteers or they were recruited from the participant pool at Koç University and were compensated with extra course credit. 


\subsubsection{Family Reminiscence Scale (FARS).}

FARS includes 10 items (see Table 1) covering the general themes of childhood experiences. The items included major physical developments and common negative and positive experiences. Participants rated the items on a 5-point scale, with higher scores indicating more frequent communication.

\subsubsection{Procedure.}

Data were collected using an online survey. Participants first read research information and gave consent to participation. Then they completed the FARS items.

\subsubsection{Data analysis.}

Analyses were conducted using SPSS 23.0 (SPSS Inc., Chicago, Illinois). In accordance with the conventional approach in exploratory factor analysis (Tabachnick \& Fiddell, 2007), communalities were examined to ensure that all items have factor loadings greater than .40. Principal components analysis (PCA) was used to evaluate the factor structure of the FARS. First, we identified the number of factors by evaluating the scree plot and eigenvalues. As we expected highly correlated factors, oblique rotation (Direct Oblimin) was used.

\subsection{Results}

The primary bend on the plot identified two factors, and eigenvalue differences between the second and the alternative third factors supported this two-factor solution. Two-factor solution with PCA accounted for $59.29 \%$ of the total variance. Seven items, describing general childhood experiences, loaded on the first factor and accounted for $48.02 \%$ of the variance. We named this factor "generalrecurrent events reminiscence" (GRER). In GRER, the item with the highest loading was about the extent mothers/fathers talked about the child's illnesses. Positive childhood experiences such as holidays were captured by this factor as well. The second factor consisted of three items and accounted for the remaining $11.27 \%$ of the total variance. These items represented first-time experiences, and was named "first-time events reminiscence" (FER). One item, Item 8, loaded on two factors with similar weights. When an item loads at .32 or higher on two or more factors (Costello \& Osborne, 2005), the conventional approach is to drop the item from the analysis. Therefore, we decided to exclude Item 8 from the scale. Item descriptions and factor loadings are presented in Table 1.

The two-factor solution was considered adequate since within each factor, items were conceptually related and despite the use of an oblique rotation method, loadings to GRER and FER factors were far from close. We also found good internal consistency for both factors (alpha $=.86$ for GRER, alpha $=$ .75 for FER) which were correlated $(r=.51, p<001)$.

We also compared men and women on their scores for the two factors. We used t-tests for unequal variances, as Levene's test indicated significantly different variances, There were significant differences between males and females on GRER, $t(228.48)=2.72, p<.01$; and on FER, $t(240.39)=2.07, p<.05$, showing that women were communicated more frequently on both unique experiences and generalrecurrent events. Table 2 presents descriptive statistics in in more detail. 
Table 1. Factor loadings of EFA

\begin{tabular}{|c|c|c|c|}
\hline & How often did your mother/father ... & $\begin{array}{c}\text { Factor 1 - } \\
\text { GRER } \\
\text { (General- } \\
\text { Recurrent } \\
\text { Events } \\
\text { Reminiscing) } \\
\end{array}$ & $\begin{array}{c}\text { Factor } 2 \text { - FER } \\
\text { (First } \\
\text { Experiences } \\
\text { Communication) }\end{array}$ \\
\hline Item 4 & $\begin{array}{l}\text {... talk about the illnesses and injuries that you had } \\
\text { when you were a child? }\end{array}$ & .827 & -.163 \\
\hline Item 3 & ... talk about your mischievousness as a child? & .748 & .026 \\
\hline Item 7 & $\begin{array}{l}\text {... talk about any an event that you were very upset } \\
\text { (i.e.crying) when you were a child? }\end{array}$ & .668 & .086 \\
\hline Item $8^{*}$ & $\begin{array}{l}\text {... show your childhood pictures or videos when they } \\
\text { were talking about your childhood experiences? }\end{array}$ & .649 & .588 \\
\hline Item 2 & $\begin{array}{l}\text {... talk about the home that you are living during your } \\
\text { childhood? }\end{array}$ & .600 & .149 \\
\hline Item 6 & $\begin{array}{l}\text {... talk about the toys you were playing when you were } \\
\text { a child? }\end{array}$ & .587 & .200 \\
\hline Item 5 & $\begin{array}{l}\text {... talk about any holiday experience that you had when } \\
\text { you were a child? }\end{array}$ & .546 & .248 \\
\hline Item 10 & ... talk about how you started walking? & .383 & .864 \\
\hline Item 9 & ... talk about how you started talking? & .058 & .860 \\
\hline Item 1 & ... talk about your first birthday? & .263 & .473 \\
\hline
\end{tabular}

*Excluded Item

\subsection{Discussion}

Our major goal was to assess the frequency of parental reminiscing during early childhood. We proposed FARS, a self-report measure in which adults rate how much their mothers and/or fathers used to talk with them about their childhood experiences. We found two related factors, one focusing on firsttime experiences and the other capturing events commonly encountered during childhood. Overall, the scale provided adequate psychometric properties.

One thing to note is that first-time experiences were clearly distinguished from other childhood events. This is not surprising, because first-time experiences constitute distinctive events, not only for the children, but also the parents (Demiray, Gülgöz, \& Bluck, 2009). Even though parents may have previously observed such events with siblings, first-time experiences still represent meaningful milestones and are likely to draw remarkable attention.

We had expected valence to discriminate the reminiscing factors, however, general-recurring events with negative and positive valences were represented under a single construct. One reason for this may be very straightforward: Communicative parents talk about negative and positive events frequently, and those who are less communicative may talk less about both event types. Alternatively, the frequency of reminiscing may be a parent- or relationship-specific characteristic, reflecting the affective closeness in the dyad, irrespective of the valence of the events.

Another issue was the elimination of Item 8 from the scale. This item did not focus on "talking" behavior, but on the utilization of various media during reminiscing. It is likely that parents use pictures or videos in their conversations with children to support reminiscence with enriched visual 
representations. Item 8 was thus loading indiscriminately on both factors. We excluded this item from the final scale culminating in a structurally stronger measure.

Finally, findings regarding gender differences were in line with the literature, indicating the effectiveness of FARS in capturing the established patterns of communication with different genders.

\section{Study 2}

Study 1 demonstrated the statistical and conceptual reliability of FARS to assess the frequency of parental reminiscing. Study 2 aimed to validate the factorial solution of FARS in an independent sample using confirmatory factor analysis (CFA). This is important for two reasons. First, CFA is more restrictive than exploratory factor analysis, as it involves model testing in which item-construct relationships are pre-specified (Brown, 2015). Second, with CFA, we examined the measurement invariance across gender and age groups. We also asked participants to report the earliest childhood memories to examine FARS in relation with the phenomenological features of childhood events.

Table 2. Factor scores across gender (study 1, $2 \& 3$ ) and age groups (study $2 \& 3$ )

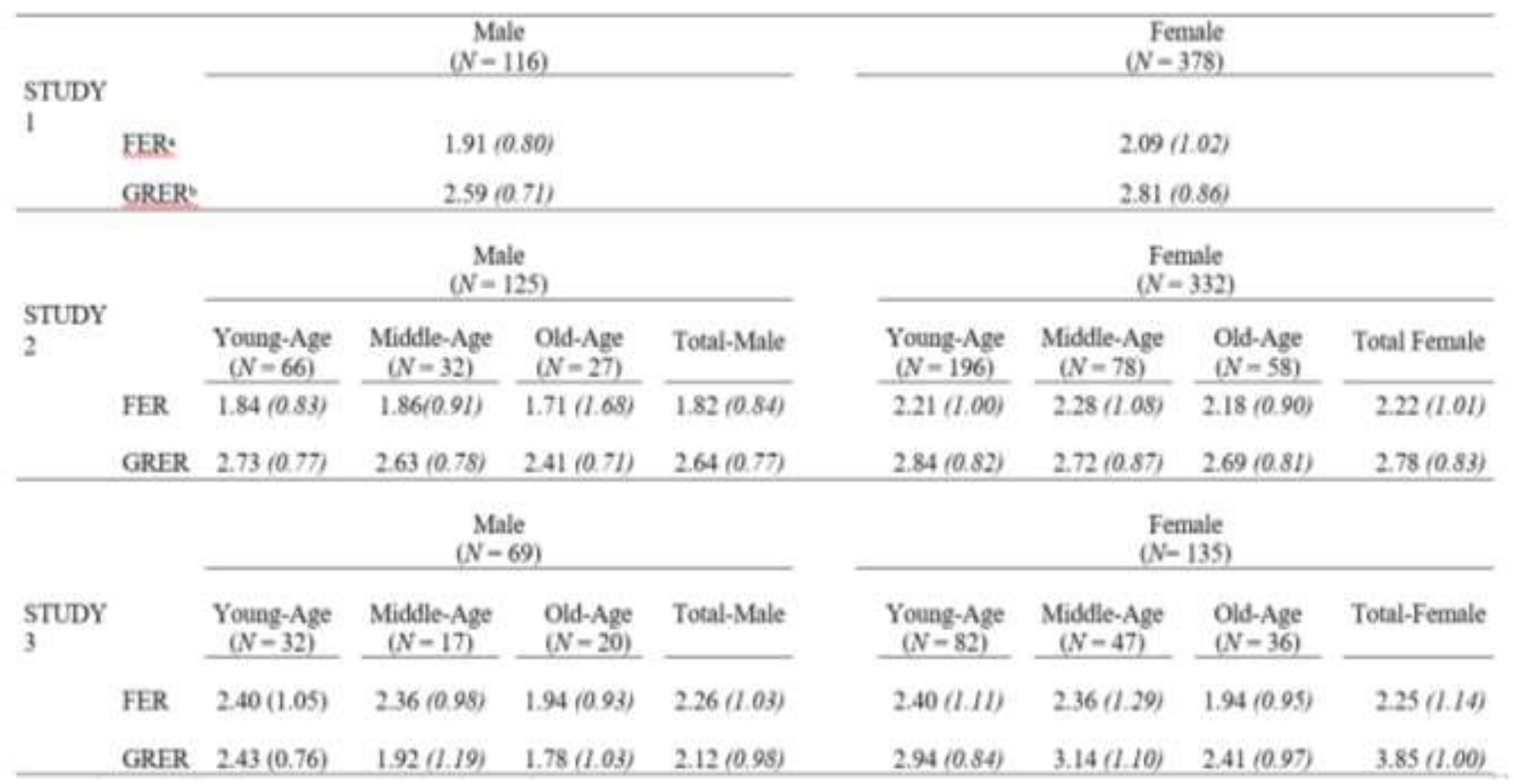

${ }^{a}$ FER refers to the first-time events reminiscing factor of FARS

${ }^{\mathrm{b}}$ GRER refers to the general-recurrent events reminsicing factor of FARS

\subsection{Method}

\subsubsection{Participants.}

We recruited 458 Turkish adults $\left(M_{\text {age }}=31.82, S D_{\text {age }}=10.16,72.6 \%\right.$ female $)$ with an age range of 18 to 65 . Participants were divided into three age groups (See Table 2): youngest (18- 30 years), middleaged (31-50 years), and the oldest (51- 68 years). Participants were recruited via social media and volunteered to participate. 


\subsubsection{Measures and Procedure}

Participants received an online survey including two sections. In the first section, the autobiographical memory section, they reported their earliest memory. After their written narratives for the earliest memories, they were asked to date their earliest memories and to rate its importance, vividness, imagery, emotional intensity, emotional valence, and rehearsal frequency. They also rated their confidence level about their recollection. These were items commonly used to assess phenomenology in autobiographical memory research (i.e., Demiray et al., 2009). In the second section of the survey, individuals completed the 9-item version of the FARS.

\subsection{Results}

Confirmatory factor analyses. The hypothesized model tested in the confirmatory factor analysis (CFA) was specified in accordance with the two-factor solution of FARS (Study 1). CFA was conducted using IBM AMOS 21.0 (Arbuckle, 2014).

We used multiple fit indices to evaluate the fitness of the model. First, we examined the Chi-square $\left(\chi^{2}\right)$ and the degrees of freedom $(d f)$ values, for which $\chi^{2} / d f$ values between 1 and 5 are considered acceptable. However, Chi-square values are very sensitive to sample size and depending on whether the sample is too large or too small, it may lead to biased conclusions by inflating or diminishing the model fit (Kline, 2005). Therefore, we evaluated the model using other indices including Comparative Fit Index (CFI) and Normed Fit Index (NFI) (Bentler, 1990), Tucker-Lewis Index (TLI, Tucker \& Lewis, 1973), Incremental Fit Index (IFI; Bollen, 1989), and Root-Mean-Square Error of Approximation (RMSEA; Steiger, 1990). As suggested by Kline (2005), good fit is indicated when $\chi^{2} / d f<3.00$; TLI, CFI, NFI, IFI $>.90$, and RMSEA <.08.

The two-factor solution of the FARS yielded good fit, $\chi^{2}(91.71) / d f(26)=3.52, p<.01$, CFI = .96, $\mathrm{NFI}=.95, \mathrm{IFI}=.96, \mathrm{RMSEA}=.06$. Although the model was significant, $\left(\chi^{2}\right) / d f$ ratio, and other fit indices indicated that the model was appropriate. Regression weights were above .50 for all items and the two factors were highly correlated, $r=.60$ as they were in Study 1.

\subsubsection{Measurement invariance for FARS.}

Measurement invariance was tested using nested models, each of which was gradually more constrained. A non-significant change in Chi-square compared to the preceding model indicated measurement invariance for the target model. First, we tested for configural or pattern invariance that assessed whether factors were indicated with the same items in each group. Next, we tested for metric invariance in which factor loadings were considered equal across groups. Finally, we proceeded to test the scalar invariant model in which both intercepts and factor loadings were constrained to be equal across groups. Only if scalar invariance was established, further analyses tested for the invariance of covariances and residuals (Van de Schoot, Lugtig, \& Hox, 2012).

\subsubsection{Gender}

Configural invariance was established across men and women (Table 3). In the second step, the factor-invariant model was non-significant, supporting the equivalence of factor loadings across groups, $\Delta \chi^{2}(\Delta d f)=4.23(7), p=.75$. However, the model of scalar invariance yielded a significant $\Delta \mathrm{CMIN}$, indicating that, although meaning of the constructs was comparable across groups (metric invariance), levels of underlying items were different.

\subsubsection{Age groups}

In order to form meaningful age groups, we considered the reminiscence bump phenomenon which refers to recalling significantly more memories from the ages between 18 and 30 (Demiray, et al., 2009). We grouped them such that participants with ages 18-30, 31-50, and 51-68 were referred to as the 
youngest, middle-aged, and oldest groups, respectively. The $\triangle \mathrm{CMIN}$ was non-significant for all invariance models across the three age groups, $\Delta \chi^{2}(\Delta d f)=10.70(14), p=.71$ for metric invariance model, $\Delta \chi^{2}(\Delta d f)=32.25(28), p=.26$, for scalar invariance model, and $\Delta \chi^{2}(\Delta d f)=57.35(42), p=.05$, for the invariance of residuals. This ensured that the latent constructs were measured identically across all age groups.

\subsubsection{FARS and memory phenomenology.}

We examined the relationship between the FARS factors and the features of earliest memories with the assumption that communication about past experiences influences how individuals remember these memories. The factor of reminiscing about first experiences (FER) was related to the extent earliest memories were shared $(r=27, p<.01)$ and thought about $(r=.16, p=.001)$. FER was also positively associated with confidence $(r=.12, p=.016)$, emotionality $(r=.10, p=.032)$, and vividness $(r=.11, p$ $=.039)$ of earliest memories. In addition, FER was associated with reporting memories from an earlier age $(r=.18, p<.01)$. The general-recurrent events reminiscing (GRER) factor, however, was only related to the frequency of thinking $(r=.24, p<.01)$, and sharing $(r=.14, p=.013)$ of earliest memories

Table 3. Fit indices for the measurement model and invariance testing

\begin{tabular}{|c|c|c|c|c|c|c|c|c|}
\hline & CMIN df & df & CFI & NHI & IFI & $\mathrm{TH}$ & RMSEA & ChangeCMIN (p) \\
\hline Model I & 3.52 & 26 & 96 & 95 & 96 & 95 & 06 & \\
\hline Model 2 & 2.27 & 52 & 96 & 95 & 96 & 94 & os & \\
\hline Model 3 & 207 & 99 & 96 & 93 & 96 & 95 & 04 & $4.234 .75)$ \\
\hline Model 4 & 221 & 66 & 95 & 93 & 95 & 94 & .05 & $2320(.02)$ \\
\hline Modet 5 & 2.03 & 78 & 95 & 93 & 95 & 93 & .05 & \\
\hline Model is & 1.84 & 92 & 95 & 93 & 94 & -94 & 04 & $11.66(.63)$ \\
\hline Model 7 & 1.81 & 106 & 95 & 92 & 94 & 94 & 04 & $3327(23)$ \\
\hline Model 8 & 181 & 120 & 24 & 91 & 93 & 94 & .04 & $58.16 r .50)$ \\
\hline Model 9 & 3.34 & 52 & 95 & 92 & 94 & 93 & .06 & \\
\hline Model to & 3.08 & 59 & 98 & 94 & 95 & 94 & 05 & $\sin (25)$ \\
\hline Modet il & 3.26 & 66 & 34 & 92 & 24 & 94 & .06 & $3212(.01)$ \\
\hline
\end{tabular}

Model 1. CFA (Whole Sample - Study 2)

Model 2. CFA (CFA across Gender Groups - Default Model), Model 3. CFA (CFA across Gender Groups Metric Invariance), Model 4. CFA (CFA across Gender Groups - Scalar Invariance)

Model 5. CFA (CFA across Age Groups - Default Model), Model 6. CFA (CFA across Age Groups - Metric Invariance), Model 7. CFA (CFA across Age Groups - Scalar Invariance), Model 8. CFA (CFA across Age Groups - Residual Invariance)

Model 9. CFA (CFA across Cultures - Default Model), Model 10. CFA (CFA across Cultures - Metric

Invariance), Model 11. CFA (CFA across Cultures - Scalar Invariance).

Last, when we examined whether factor scores differed in relation to age and gender, we found no differences across age groups but found a gender difference in FER scores such that women were communicated more than men about first time experiences (See Table 2).

\subsection{Discussion}

Study 2 supported the two-factor model of FARS and further demonstrated the scale invariance across gender and age groups. Ensuring invariance was substantially important, because vast evidence has shown gender differences in parental communication (Fivush, 2011) and regarding age, we expected 
that changing attitudes across generations may influence the nature of parental communication. However, the model was invariant across both groups, pointing out the stability of reminiscence across males and females as well as different age groups. The two factors of FARS, reminiscing on first-time experiences (FER) and reminiscing on general-recurrent events (GRER), were differentially associated with the phenomenological features of the earliest memory, supporting for the distinctiveness of the reminiscing content in the organization of childhood memories.

\section{Study 3}

Culture-based differences have been documented in childhood amnesia research (Wang, 2006; Wang \& Conway, 2006) and social-interactionist perspective argues that such differences arise from the communicative context. The extent and the form of reminiscing that parents adopt in their interactions with the child is reflected on how individuals recall their early experiences (Nelson \& Fivush, 2004). In line with the knowledge that cultural variation in communication patterns exist, we aimed to demonstrate the invariant factorial structure of FARS in a different society to ensure the content specified in each item is represented similarly across cultures.

We also examined the narrative content in the earliest memories to test whether frequency of early reminiscing was reflected on the narrative structure of the earliest memories. Recent evidence showed that it is the child-directed reminiscing that facilitates subsequent remembering, especially with the inclusion of temporal and spatial details as organizational markers of the event (Reese et al., 2008). In relation to FARS, such content specification appeared to be more meaningful because first-time events represent unique experiences, therefore, they are more specific in terms of time and context. Accordingly, we expected early family reminiscence, particularly on first-time, unique events to be associated with increased detail and self-reference in reports of the earliest memories.

Table 4. Bivariate correlations of reminiscing factors \& remembering (Study 3)

\begin{tabular}{|c|c|c|c|c|c|c|c|c|c|c|c|}
\hline & 1 & 2 & 3 & 4 & 5 & 6 & 7 & 8 & 9 & 10 & 11 \\
\hline 1.FER ${ }^{\mathrm{a}}$ & 1 & $.69^{* * *}$ & $-.25^{* *}$ & $.26^{* *}$ & $.24^{* *}$ & $.35^{* *}$ & $.30^{* *}$ & .10 & $.22^{* *}$ & $.39^{* *}$ & $.19^{* *}$ \\
\hline 2.GRER ${ }^{\mathrm{b}}$ & & 1 & $-.27^{* *}$ & $.33^{* *}$ & $.28^{* *}$ & $.32^{* *}$ & $.26^{* *}$ & .12 & $.20^{* *}$ & $.34^{* *}$ & .09 \\
\hline 3.Age $\mathrm{C}^{\mathrm{C}}$ & & & 1 & -.07 & -.04 & -.01 & .02 & .04 & -.01 & -.02 & $-.21^{* *}$ \\
\hline 4.Valence & & & & 1 & $.21^{* *}$ & $.16^{*}$ & $.30^{* *}$ & .09 & .12 & $.24^{* *}$ & .11 \\
\hline 5.Importance & & & & & 1 & $.62^{* * *}$ & .48 & $.41^{* *}$ & $.43^{* *}$ & $.40^{* *}$ & $.51^{* *}$ \\
\hline 6.Emotionality & & & & & & 1 & .69 & $.44^{* *}$ & $.49^{* *}$ & $.35^{* *}$ & $.45^{* *}$ \\
\hline 7.Reliving & & & & & & & 1 & $.35^{* *}$ & $.49^{* *}$ & $.35^{* *}$ & $.48^{* *}$ \\
\hline 8.Imagery & & & & & & & & 1 & $.44^{* *}$ & $.25^{* *}$ & $.53^{* *}$ \\
\hline 9.Thinking & & & & & & & & & 1 & $.58^{* *}$ & $.43^{* *}$ \\
\hline 10.Talking & & & & & & & & & & 1 & $.42^{* *}$ \\
\hline 11.Self- & & & & & & & & & & & 1 \\
\hline Relevance & & & & & & & & & & & \\
\hline
\end{tabular}




\subsection{Method and Procedure}

\subsubsection{Participants}

We recruited 204 adults $\left(M_{\text {age }}=39.46, S D_{\text {age }}=11.88 ; 56.9 \%\right.$ female $)$ using Amazon Mechanical Turk. Reliability of the survey was secured by using several strategies (e.g., Mason \& Suri, 2011), such as using background timer and filler items as an attention check to prevent random answers. We only included MTurk workers who had approval rates of $95 \%$ or higher to ensure high-quality data. All participants were residents of the United States.

\subsubsection{Procedure}

As in Study 2, Participants first reported their earliest childhood memory. We specifically requested a specific event that occurred at a particular time and place, then they provided a short narrative and indicated the date for that event. Finally, participants completed FARS. Participants who appropriately completed the survey were presented with a debriefing screen and were compensated with $\$ 1.00$.

\subsection{Results}

\subsubsection{CFA and measurement invariance}

We first examined whether the two-factor solution of FARS was also appropriate for the US sample and investigated whether latent factors were comparable across cultures. Study 2 sample served as the comparison group when testing measurement invariance. The two samples were not different from each other in terms of age and gender. Invariance testing followed the steps summarized in Study 2.

The two-factor model fit the US data well, $\chi^{2}(76.32) / d f(26)=2.93, p<.01, \mathrm{CFI}=.95, \mathrm{NFI}=.92$, IFI $=.94$, RMSEA $=.07$. As the absolute (RMSEA < .08) and comparative fit indices (CFI, NFI, IFI > .90) were in line with the conventional criteria (Kline, 2005; Byrne, 1994), we considered model significance as negligible. The two factors were correlated $(r=.65)$ and the internal consistency of FER (alpha $=.85)$ and GRER (alpha $=.86$ ) were high, showing the reliability of these two factors also in the US sample.

Multi-group CFA using the data from the US and Turkey (Study 2) ensured configural invariance across cultures. Metric invariant model was also non-significant $\Delta \chi^{2}(\Delta d f)=10.41(7), p=.16$. However, $\Delta \chi^{2}$ was significant for the scalar invariant model, which allowed for cross-cultural comparison while ensuring similar representation of factors across groups. Although, this indicated that factors were similarly represented across the American and Turkish samples, there might be group differences in the item base. However, we did not further modify the model because cross-cultural differences are likely with differing family communication patterns and this does not violate the validity of the factorial structure of the model.

\subsubsection{The relationship between FARS and phenomenology of the earliest memories}

Bivariate correlations tested for the relevance of FARS factors with the representation of earliest memories. We found comparable patterns of correlation for FARS factors. Early family reminiscence, in general, was related to more frequent rehearsal of the earliest memories, both voluntarily and involuntarily. Also, high scores in FARS factors were associated with greater experience of positivity, emotional intensity, and reliving during the recall. Only FARS factors were distinguished only in terms of self-relevance, that is, only reminiscing on first-time events (FER) was related to the extent of selfrelevance attributed to the earliest events. Table 4 presents the correlation pattern between FARS factors and memory characteristics.

\subsubsection{The relationship between FARS and the narrative structure}

Bivariate correlations were conducted to test how FARS factors were related to the narrative characteristics of the earliest memories. The memories were long enough to convey the specificity of 
the experience, however, we focused on dimensions of emotionality and the self-focus. Linguistic Inquiry for Word Count (LIWC; Pennebaker, Boyd, Jordan, \& Blackburn, 2015) was used for the analyses of the memory content with specifically five linguistic indicators: overall affective processing, emotional positivity, emotional negativity, and the use of $I$ in the entire report. The emotional tone index was also derived as a measure of overall positivity in the narrative (Cohn, Mehl, \& Pennebaker, 2004).

Table 5. Partial correlations of reminiscing factors with linguistic indicators in the narratives (Study 3)

\begin{tabular}{|c|c|c|c|c|c|c|c|}
\hline & 1 & 2 & 3 & 4 & 5 & 6 & 7 \\
\hline 1.FER ${ }^{\mathrm{a}}$ & 1 & $.69^{* *}$ & $.16^{*}$ & $-.20^{* *}$ & $.16^{*}$ & $.18^{*}$ & $-.27^{* *}$ \\
\hline 2. GRER ${ }^{b}$ & & 1 & $.24^{* *}$ & $-.17^{*}$ & .14 & .09 & $-.25^{* *}$ \\
\hline 3.PosEmo ${ }^{\mathrm{c}}$ & & & 1 & -.12 & -.01 & -.01 & .08 \\
\hline 4.NegEmo ${ }^{c}$ & & & & 1 & $.21^{* *}$ & $.27^{* *}$ & .06 \\
\hline 5.Pronouns & & & & & 1 & $.25^{* *}$ & $.21^{* *}$ \\
\hline 6.Person-Pronouns & & & & & & 1 & $.19^{* *}$ \\
\hline 7.Age ${ }^{\mathrm{d}}$ & & & & & & & 1 \\
\hline
\end{tabular}

${ }^{\mathrm{a}}$ FER refers to the first-time events reminiscence factor of FARS

${ }^{\mathrm{b}}$ GRER refers to the general-recurrent events reminiscence factor of FARS

${ }^{\mathrm{c}}$ Age represents the individual's age at the time of the earliest event

Partial correlation analyses were conducted using the total number of words in the narrative as the control variable. The pattern of correlations was in line with our expectations. Frequent reminiscing on early experiences was associated with the use of more positive and less negative words, making the overall emotional tone of the narrative more positive. Total use of pronouns was associated with both FARS factors, showing that frequent family reminiscing was related to more references to both self and others. However, the relationship between the use of personal pronouns was related only with the communication on FER. Correlation coefficients are presented in Table 5.

\subsection{Discussion}

Invariance models demonstrated the equivalence in the conceptualization of latent factors across samples from Turkey and United States. Consistent meaning reminiscing constructs further contributed to the psychometric reliability of the scale across cultures. Phenomenological features have relatively similar pattern of relationships with FARS. Analysis of the narrative structure in relation with FARS served as a further validation of FARS, demonstrating how frequency of parent-child talk was reflected on the adult narratives of the earliest memories.

\section{Discussion}

It has been consistently shown that the way parents communicate with their children has a profound effect on the development and organization of autobiographical memory. Here, we proposed a novel measure for assessing adults' reminiscence experiences in their family during early childhood. FARS was composed of two factors, one that represented reminiscence of first-time experiences (FER), and the other including more general-recurring events (GRER). The two-factor solution was consistent and the latent factors were found to be comparable across groups of age and gender. This is an important strength of the scale because latent constructs of reminiscence substantially maintain their meaning irrespective of the variance in these major demographic variables. 
Fitness and invariance of the scale were demonstrated across cultures as well. We found the twofactor solution to result in good fit for the US and Turkish samples, supporting FARS to be used comparably in different societies. This conceptual equivalence of the constructs indicated that despite any potential differences in the frequency of parental reminiscing about early experiences, the distinction between the two reminiscence factors is perceived similarly across the two countries.

Here it is important to underline that FARS has conceptual significance also with respect to the autobiographical remembering. Relying on the evidence showing the link between early parental reminiscing and autobiographical memory formation (Fivush et al., 2006), we focused on phenomenological features of earliest memories to validate FARS. As we expected, two factors of FARS were distinguished with respect to the way earliest memories were recalled. Parental reminiscing of general-recurring events was related only to the rehearsal, whereas reminiscing of first-time events was additionally related to the affective and recollective features of the earliest memory. This pattern can be explained by the distinct functions of each factor. Reminiscing about first-time events constitutes unique communication episodes, specifically emphasizing the child's transitional experiences. These interactions facilitate the integration of the events in one's sense of self as milestones in one's life story (Demiray, et al., 2009) and cultural life scripts (Berntsen \& Rubin, 2004). Irrespective of emotional valence, reminiscing is highly specific, allowing the child to retain qualitative aspects of the event. On the other hand, parental talk about general-recurring events serves rehearsal, but also involves much repetition and does not necessarily target the child. In that sense, GRER may represent the extent of recounting (Reese \& Brown, 2000) aiming to gather information. Therefore, despite frequent consolidation through GRER, recounted experiences are retained in a less detailed and more abstract manner.

It is important to note that Study 3 demonstrated significant relationships between GRER and recollective and emotional properties of the earliest memories as well. One possible explanation for this could be the difference in the age range in two samples. Since earliest memories are temporally closer for younger participants, they may be well-preserved, revealing the link between early reminiscence and memory phenomenology. We believe further research will shed light on the dynamics moderating the manifestation of FARS factors on remembering.

\subsection{Narrative analyses served as a further validation of FARS.}

Positivity in the emotional tone of narratives was related to the frequent family reminiscing on early experiences, which may be a function of enhanced parental supervision for framing the past. Furthermore, the extent individuals utilize a self-perspective in their earliest reports was shown to be related to the frequency of early reminiscence on first-time, mostly the accomplishments. It is possible that parental emphasis on such unique events has a role in guiding subsequent rehearsal processes, resulting in adult memories to be reported from a more salient self-perspective.

\section{Conclusions}

We proposed a practical measurement tool that has important implications for understanding the dynamics of parent-child reminiscing when testing adult samples. Relative frequency of the content communicated in early interactions revealed substantial information not only regarding the representation of early experiences, but also for the relational quality of parental communication. Individuals who were exposed to rich parental communication in the early childhood reported earlier, more vivid childhood memories, showing the enduring influence of the early communicative context in later years. Linguistic input may have contributed to better encoding of early experiences, leading more 
permanent representations of these events to be later recalled. But it is also possible that early linguistic input may have provided diverse and strong cues associated with the early event, so that individuals, when they are adults, can easily figure out the retrieval route and access vivid representations of the event. Not only a phenomenological advancement, linguistic style individuals adopt when they are narrating their earliest memories are linked with the frequency of early parental reminiscing. Current work emphasizes the role of parental communication in recalling the earliest memories and brings forward the need to examine the underlying mechanisms that guide the organization of the memories through development. Family Reminiscence Scale has been in that sense one of the few measures (i.e., Fivush et al., 2009) that targets early linguistic context using retrospective reports. Cross-cultural applicability is also encouraging in that the scale can be used in future research where the current assumptions on the functional role of linguistic input in autobiographical remembering may be addressed.

\section{Ethics Committee Approval}

The author confirms that the ethical approval was obtained from Koç University Committee on Human Research (Approval Date and Number: 2014. 167.IRB3.113).

\section{References}

Alea, N., \& Bluck, S. (2003). Why are you telling me that? A conceptual model of the social function of autobiographical memory. Memory, 11(2), 165-178.

Arbuckle, J. L. (2014). Amos (Version 23.0) [Computer Program]. Chicago: IBM SPSS.

Artioli, F., Cicogna, P. C., Occhionero, M., \& Reese, E. (2012). “The people I grew up with”: The role of sociodemographic factors in early memories in an Italian sample. Memory, 20(2), 189-197.

Bentler, P. M. (1990). Comparative fit indexes in structural models. Psychological Bulletin, 107, 238246.

Berntsen, D., \& Rubin, D. C. (2004). Cultural life scripts structure recall from autobiographical memory. Memory \& cognition, 32(3), 427-442.

Bollen, K. A. (1989). Structural equations with latent variables. New York: Wiley.

Brown, T. A. (2015). Confirmatory factor analysis for applied research. Guilford Publications.

Demiray, B., Gülgöz, S., \& Bluck, S. (2009). Examining the life story account of the reminiscence bump: Why we remember more from young adulthood. Memory, 17(7), 708-723.

Fivush, R. (2011). The development of autobiographical memory. Annual review of Psychology, 62, 559-582.

Fivush, R., \& Vasudeva, A. (2002). Remembering to relate: Socioemotional correlates of mother-child reminiscing. Journal of Cognition and Development, 3, 73-90.

Fivush, R., Haden, C. A., \& Reese, E. (2006). Elaborating on elaborations: Role of maternal reminiscing style in cognitive and socioemotional development. Child Development, 77, 1568-1588. 
Fivush, R., Marin, K., McWilliams, K., \& Bohanek, J. G. (2009). Family reminiscing style: Parent gender and emotional focus in relation to child well-being. Journal of Cognition and Development, 10(3), 210-235.

Hedrick, A. M., Haden, C. A., \& Ornstein, P. A. (2009). Elaborative talk during and after an event: Conversational style influences children's memory reports. Journal of Cognition and Development, 10(3), 188-209.

Jack, F., MacDonald, S., Reese, E., \& Hayne, H. (2009). Maternal reminiscing style during early childhood predicts the age of adolescents' earliest memories. Child Development, 80,496-505.

Kingo, O. S., Berntsen, D., \& Krøjgaard, P. (2013). Adults' earliest memories as a function of age, gender, and education in a large stratified sample. Psychology and Aging, 28(3), 646.

Kline, R. B. (2005). Principles and practice of structural equation modeling. (2nd Edition ed.). New York: The Guilford Press.

Kuebli, J., \& Fivush, R. (1992). Gender differences in parent-child conversations about past emotions. Sex Roles, 27, 683-698.

Laible, D. (2011). Does it matter if preschool children and mothers discuss positive vs. negative events during reminiscing? Links with mother - reported attachment, family emotional climate, and socioemotional development. Social Development, 20(2), 394-411.

Nelson, K., \& Fivush, R. (2004). The emergence of autobiographical memory: A social cultural developmental theory. Psychological Review, 111, 486-511.

Oppenheim, D., \& Koren-Karie, N. (2014). Parental insightfulness and child-parent emotion dialogues: Their importance for children's development. In M. Mikulincer \& P. Shaver (Eds), Mechanisms of social connection: From brain to group (pp. 205 - 220). New York: American Psychological Association.

Peterson, C., Smorti, A., \& Tani, F. (2008). Parental influences on earliest memories. Memory, 16(6), 569-578.

Peterson, C., \& Nguyen, D. T. (2010). Parent-child relationship quality and infantile amnesia in adults. British Journal of Psychology, 101(4), 719-737.

Reese, E, \& Brown, N. (2000). Reminiscing and recounting in the preschool years. Applied Cognitive Psychology, 14(1), 1-17.

Sales, J. M., Fivush, R., \& Peterson, C. (2003). Parental reminiscing about positive and negative events. Journal of Cognition and Development, 4, 185-209.

Steiger, J. H. (1990). Structural model evaluation and modification. Multivariate Behavioral Research, $25,214-12$.

Tucker, L. R., \& Lewis, C. (1973). A reliability coefficient for maximum likelihood factor analysis. Psychometrika, 38, 1-10.

Van de Schoot, R., Lugtig, P., \& Hox, J. (2012). A checklist for testing measurement invariance. European Journal of Developmental Psychology, 9(4), 486-492.

Wang, Q. (2006). Relations of maternal style and child self-concept to autobiographical memories in Chinese, Chinese immigrant, and European American 3-year-olds. Child Development, 77, 17941809. 
Wang, Q., Conway, M. A. (2006). Autobiographical memory, self, and culture. In Nilsson, L.-G., Ohta, N. (Eds.), Memory and society: Psychological perspectives (pp. 9-27). New York, NY: Psychology Press.

\title{
Ebeveyn-temelli hatırlama ölçeği: Erken iletişimsel ortam değerlendirme aracının psikometrik özellikleri)
}

\begin{abstract}
$\ddot{O} \mathbf{z}$
Ebeveynlerin teşvik edici iletişimlerinin erken çocukluk dönemlerine dair otobiyografik anıların hatırlanmasına katıkıda bulunduğu sayısız çalışma tarafından gösterilmiştir. Yapılan çalışmada, Ebeveyn-Temelli Hatırlama Ölçeğini geliştirerek yetişkinlerin çocukluk dönemlerinde ebeveynleri ile deneyimleri hakkında ne derece iletişim kurduklarını değerlendirildi. Psikometrik özelliklerinin incelenmesinin ardından, ölçeğin farklı kültürlerdeki yetişkinlerin hem erken dönem anılarını nasıl hatırladıkları gösterildi. Bu bağlamda ilk çalışmada, ilk deneyimlerin (örn., ilk yürüme) hatırlanması ve genellenmiş-tekrar eden olayların hatırlanması olarak ölçeğin iki faktörlü yapısı ortaya kondu. Ardından, bağımsız bir örneklemde ölçeğin bu faktör yapısı farklı yaş ve cinsiyet gruplarındaki geçerliği gösterilerek faktörlerin çocukluk anılarını hatırlama özellikleri ile ilişkileri incelendi. Son olarak, çalışma, eşdeğer bir Amerika örnekleminde tekrarlanarak faktör yapısının geçerliği bu örneklem ile de desteklenmiş̧ir. Ayrıca, erken dönem çocukluk anılarının hatırlama özellikleri ile faktörlerin ilişkisindeki benzer ve özgün yapılar Amerika örnekleminde de gösterilmiştir. Sonuç olarak yapılan üç çalışmada, Ebeveyn-Temelli Hatırlama Ölçeği gelişimsel dönemde maruz kalınan dilin niteliği ve sıklığını değerlendiren bir ölçüm aracı olarak yetişkinlerde geçerlik ve güvenilirliği farklı yaş, cinsiyet ve kültür gruplarında gösterilmiştir. Tutarlı olarak, ölçeğin erken dönemde aile içi iletişime bağlı olarak yetişkinlerde erken dönem anıları hatırlanırken görülebilecek dilsel ve fenomenolojik farklılıkları yordadığı görülmüştür.
\end{abstract}

Anahtar sözcükler: Erken dönem anıları; çocukluk amnezisi,; aile-temelli hatırlama; diz analizi,; ölçek geliştirme

\section{AUTHOR BIODATA}

Sezin Öner, Ph. D., Assistant Professor, Department of Psychology, Kadir Has University, İstanbul, Turkey.

Berivan Ece, Ph. D., Assistant Professor. Department of Psychology, Koç University, İstanbul, Turkey.

Sami Gülgöz, Ph. D., Professor. Department of Psychology, Koç University, İstanbul, Turkey. 